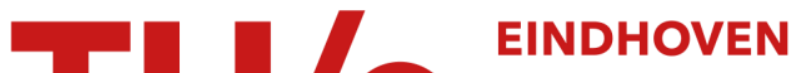 \\ UNIVERSITY OF \\ TECHNOLOGY
}

\section{Chemorheology of a highly filled epoxy compound}

Citation for published version (APA):

Spoelstra, A. B., Peters, G. W. M., \& Meijer, H. E. H. (1996). Chemorheology of a highly filled epoxy compound. Polymer Engineering and Science, 36(16), 2153-2162. https://doi.org/10.1002/pen.10612

DOI:

10.1002/pen.10612

Document status and date:

Published: 01/01/1996

\section{Document Version:}

Publisher's PDF, also known as Version of Record (includes final page, issue and volume numbers)

\section{Please check the document version of this publication:}

- A submitted manuscript is the version of the article upon submission and before peer-review. There can be important differences between the submitted version and the official published version of record. People interested in the research are advised to contact the author for the final version of the publication, or visit the $\mathrm{DOI}$ to the publisher's website.

- The final author version and the galley proof are versions of the publication after peer review.

- The final published version features the final layout of the paper including the volume, issue and page numbers.

Link to publication

\section{General rights}

Copyright and moral rights for the publications made accessible in the public portal are retained by the authors and/or other copyright owners and it is a condition of accessing publications that users recognise and abide by the legal requirements associated with these rights.

- Users may download and print one copy of any publication from the public portal for the purpose of private study or research.

- You may not further distribute the material or use it for any profit-making activity or commercial gain

- You may freely distribute the URL identifying the publication in the public portal.

If the publication is distributed under the terms of Article 25fa of the Dutch Copyright Act, indicated by the "Taverne" license above, please follow below link for the End User Agreement:

www.tue.nl/taverne

Take down policy

If you believe that this document breaches copyright please contact us at:

openaccess@tue.nl

providing details and we will investigate your claim. 


\title{
Chemorheology of a Highly Filled Epoxy Compound
}

\author{
A. B. SPOELSTRA, G. W. M. PETERS, and H. E. H. MEIJER \\ Centre for Polymers and Composites \\ Eindhoven University of Technology \\ 5600 MB Eindhoven, The Netherlands
}

\begin{abstract}
Based on measurements of the dynamic viscosity, a strategy is proposed to find an expression that relates the viscosity of an epoxy compound during curing, to the temperature, shear rate, and degree of reaction. It appeared that the dynamic viscosity is a unique function of the effective shear rate (i.e. the product of frequency and strain) over a wide range of frequencies and strains after being corrected for the temperature. The effective shear rate dependence of the viscosity is described with a power law with an exponent that depends on the conversion. The effect of temperature is described with an Arrhenius-type equation with conversion dependent parameters. Differential scanning calorimetry is applied to determine the kinetic equation that is used, in combination with the thermal history, to obtain the conversion during the rheological measurements. The description of the viscosity gives a good prediction of the measured viscosity in the region between melting and gelation of the compound. The theories proposed in the literature to detect the gel point from dynamic experiments are examined. It is found that neither the $G^{\prime}-G^{\prime \prime}$ crossover, investigated by e.g. Tung and Dynes (1), nor the frequency-independence of $\tan (\delta)$, described by Winter $(2,3)$, can be used to determine the gel point of the given material. In contrast, the curves of $G^{\prime}$ against conversion for measurements performed at equal strain but with different thermal histories appear to converge at a conversion of $\sim 18 \%$, which agrees with the gel point determined through extraction experiments.
\end{abstract}

\section{INTRODUCTION}

$\mathrm{T}$ he materials studied are epoxy compounds used for the encapsulation of Integrated Circuits via a transfer molding process. Highly filled epoxy resins satisfy encapsulation requirements and are, therefore, almost universally accepted. For mathematical modeling of the processing of reactive materials, one needs, apart from the reaction heat and the kinetics, an expression that relates viscosity to temperature, shear rate, and degree of reaction. Furthermore, the gel point, which states a no-flow condition, needs to be determined.

In the literature only limited information can be found concerning the effect of curing on viscosity especially for highly filled (epoxy) compounds. Therefore, in this research a strategy is investigated to find the required expression.

\section{MATERLALS}

The epoxy compound studied is a fast-curing commercial compound, supplied by Synres-Almoco, based on a phenol novolac epoxy and hardener. A diglycidylether of tetra bromo bisphenol-A is added to improve the fire-resistance properties. The compound is filled with a combination of crushed silica and quartz for $69 \mathrm{wt} \%$, resulting in a solid volume content of $50 \%$. Further, it contains release agents, carbon black, and other common additives.

\section{REACTION KINETICS}

\section{Strategy}

For the cure reaction of thermosets, various rate expressions have been proposed in the literature (46). To account for the autocatalytic curing of thermosets, Kamal and Sourour (6) suggested the following expression:

$$
\dot{\alpha}=\frac{d \alpha}{d t}=\left(K_{1}+K_{2} \alpha^{m}\right)(1-\alpha)^{n}
$$

in which $n$ and $m$ represent reaction orders. The rate constants $K_{1}$ and $K_{2}$ depend on the temperature, according to an Arrhenius expression:

$$
K_{1}=k_{1} \exp \left(\frac{-\Delta E_{1}}{R T}\right), \quad K_{2}=k_{2} \exp \left(\frac{-\Delta E_{2}}{R T}\right)
$$

where $k_{1}$ and $k_{2}$ are pre-exponential factors, $\Delta E_{1}$ and $\Delta E_{2}$ are activation energies, $R$ is the gas constant and $T$ is the absolute temperature. 
For kinetic studies by means of differential scanning calorimetry (DSC), it is usually assumed that the total heat of reaction, $d H$, is proportional to the conversion, $\alpha$, of the reactants. The reaction rate then can easily be calculated from calorimetric measurements with:

$$
\dot{\alpha}=\frac{d \alpha}{d t}=\frac{1}{\Delta H} \frac{d H}{d t}
$$

where $\alpha$ is the rate of reaction, $\alpha$ is the conversion, $\Delta H$ is the total heat production at complete cure and $d H / d t$ is the differential heat flow during cure.

To study the cure kinetics by means of DSC, measurements can be conducted under isothermal (timesweep) or dynamic (temperature-scan) modes [Prime (7)]. For fast curing thermosets, isothermal experiments are inadequate since part of the reaction already takes place during heating of the sample. Therefore, in this study dynamic experiments are performed at different heating rates. By integration of $E q 3$ over the total cure-time, the heat of reaction $(\Delta H)$ is determined. The fractional conversion $\alpha(\tau)$ is likewise calculated by integrating from $t=0$ to $t=\tau$. In our analysis the trapezoidal-rule is used for numerical integration. For each heating rate a set of data is obtained, containing $T, \alpha$, and $\dot{\alpha}$.

The kinetic parameters $k_{1}, k_{2}, \Delta E_{1}, \Delta E_{2}, n$, and $m$ can be determined by fitting $\dot{\alpha}$ to the autocatalytic function of $\alpha$ and $T$, see $E q 1$, by a nonlinear least squares program. The results of all dynamic experiments are fitted simultaneously. First, the data are fitted to a simple $n^{\text {th }}$-order reaction $\left(k_{2}=0\right)$. Accordingly, these results are used to initiate the program to fit to the autocatalytic expression.

With the kinetic equation obtained, it is possible to predict the reaction rate and conversion for any temperature-history by numerical integration. In our analysis a $2^{\text {nd }}$-order Runge-Kutta integration method is used.

\section{Experimental}

DSC-measurements are carried out in a PerkinElmer DSC-7. Calibration of the calorimeter is conducted for each run, using indium (temperature, enthalpy) and zinc (temperature). Each sample contained 5 to $7 \mathrm{mg}$ of compound, sealed in a sample pan. Measurements at constant heating rate are performed at $5,10,20$, and $40^{\circ} \mathrm{C} / \mathrm{min}$, in a temperature range of 50 to $250^{\circ} \mathrm{C}$.

\section{Results and Discussion}

The heat evolved during the reaction of the compound, $\Delta H$, is directly determined by integration of the exothermal peaks from the DSC-measurements shown in Fig. 1 and is found to be $60 \mathrm{~J} / \mathrm{g}$. The conversion, calculated according to the method discussed above, is shown in Fig. 2. In Table 1 the final results of the fit are summarized. Since $m$ and $n$ are not integers it is very likely that all variables represent an average of a number of different reactions. With the kinetic

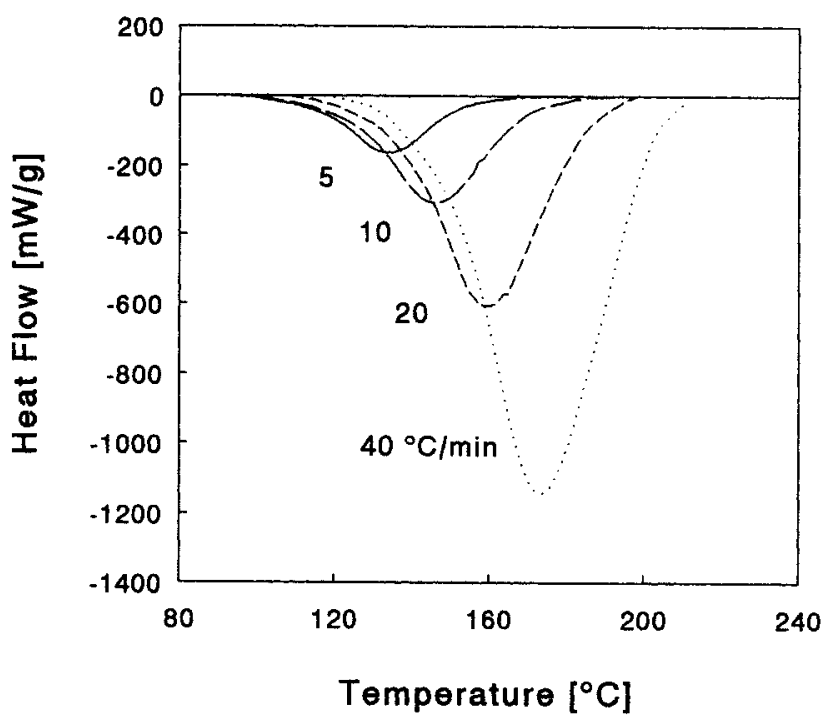

Fig. 1. Heat flow measured by DSC during cure at constant heating rate: $5,10,20$, and $40^{\circ} \mathrm{C} / \mathrm{min}$.

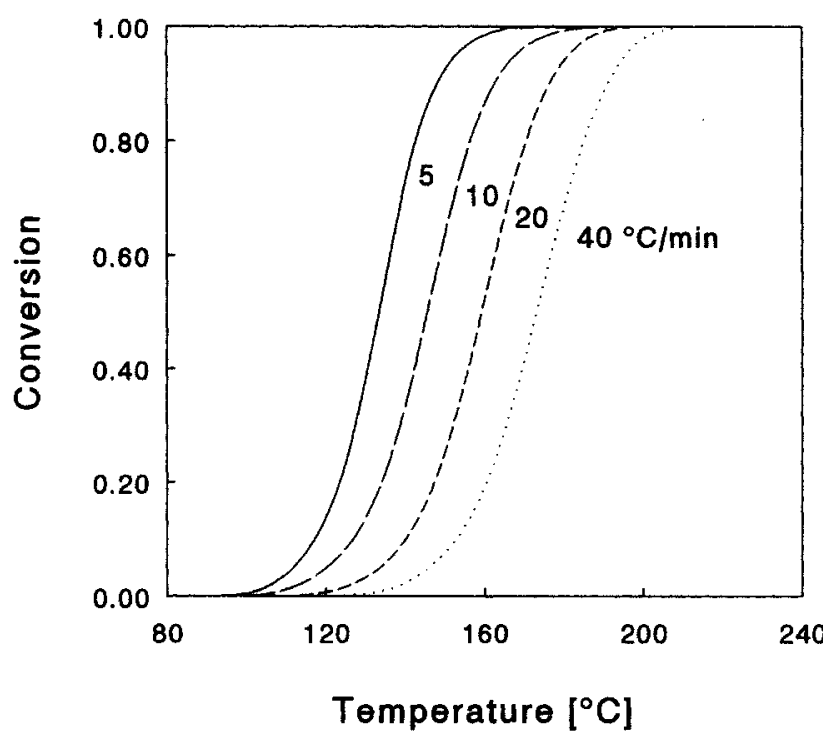

Fig. 2. Calculated conversion at constant heating rate: 5,10 , 20 , and $40^{\circ} \mathrm{C} / \mathrm{min}$.

Table 1. Kinetic Parameters.

\begin{tabular}{rlrl}
\hline$k_{1}$ & $=6.84^{*} 10^{5} \mathrm{~s}^{-1}$ & $k_{2}$ & $=1.60^{*} 10^{7} \mathrm{~s}^{-1}$ \\
$\Delta E_{1}$ & $=102 \mathrm{~kJ} / \mathrm{mol}$ & $\Delta E_{2}$ & $=72.4 \mathrm{~kJ} / \mathrm{mol}$ \\
$n$ & $=1.09$ & $m$ & $=0.45$ \\
\hline
\end{tabular}

variables obtained, the kinetic data are recalculated to check the fit, with satisfactory results (Fig. 3).

\section{RFIEOLOGY}

\section{Strateg}

The main problem with highly filled, fast curing compounds, is the difficulty to measure steady state viscosities. Capillary viscometry is not possible for different reasons. The most important one is that this method requires the same material all over the capil- 


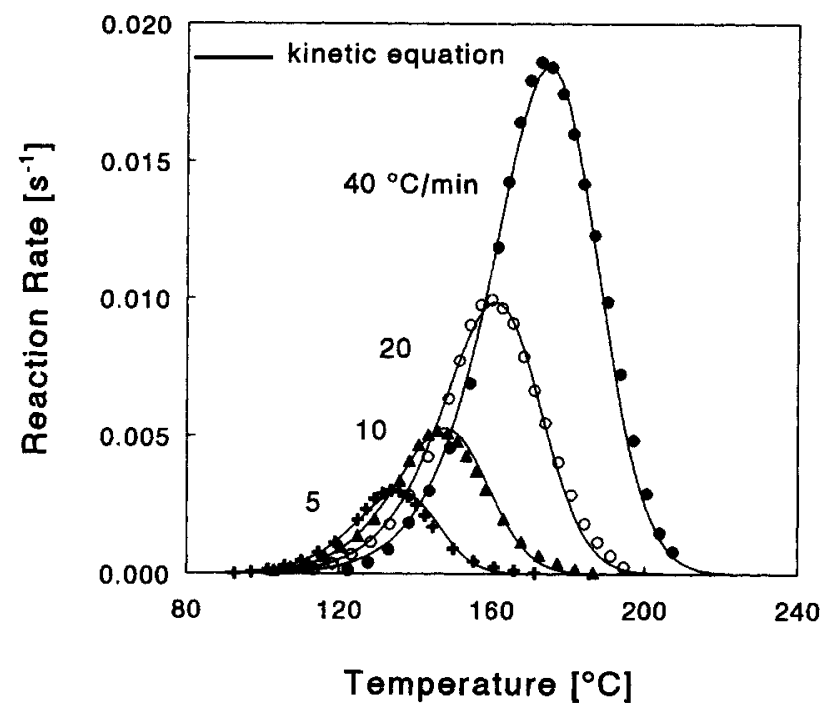

Fig. 3. Experimental data (symbols) and calculated reaction rate (full line); heating rates: $5,10,20$, and $40^{\circ} \mathrm{C} / \mathrm{min}$.

lary tube, which is not fulfilled owing to time- and place-dependent cure. For rotational viscometers, the sample will curl up during a steady state experiment due to the paste-like behavior of highly filled compounds. As a consequence, in this study, the dynamic viscosity $\left(\eta_{d}\right)$, with deformations restricted to small amplitude oscillations, is measured instead of the steady state viscosity $\left(\eta_{s}\right)$. To develop a proper viscosity model for flow simulations it is necessary, however, to translate the measured dynamic viscosities to steady state viscosities.

Roller (8) reported that for some unfilled thermosets the Cox-Merz rule (9) can be applied for conversions below the gel point:

$$
\eta_{d}(\omega)=\eta_{s}(\dot{\gamma}=\omega)
$$

The validity of this law also for filled systems is implicitly assumed by different investigators. Kitano et al. (10) observed, however, that for polyethylene and polypropylene melts filled with various solid particles, the Cox-Merz rule failed when solid volume fractions were larger than 0.1 to 0.2 . The dynamic viscosity measured at frequency $\omega$, is lower than the steady state viscosity measured at a shear rate $\dot{\gamma}=\omega$. Applying Cox-Merz would result in a too strong shear thinning behavior. This result is confirmed by Bigg (11) who reported that even at low strains dense suspensions exhibit a large strain dependency. A constitutive relation for highly filled dispersions, a model with a yield stress described by Hookean behavior below and by a Herschel-Bulkley relation above the critical stress, was reported by Doraiswamy et al. (12) who studied a $70 \mathrm{vol} \%$ suspension of silicon in polyethylene. Independently, Van den Brule (13) proposed three similar, but more general, constitutive relations containing a yield stress. One of the results of this type of constitutive model is that the dynamic viscosity at different strain levels may, approximately, be made to superimpose if plotted against an effective shear rate, defined as the product of frequency $(\omega)$ and maximum strain $\left(\gamma_{0}\right)$. Furthermore, an equivalence between the steady state viscosity and the dynamic viscosity is predicted:

$$
\eta_{s}(\dot{\gamma})=\eta_{d}\left(\omega \gamma_{0}\right)
$$

The experimental results, reported by Doraiswamy et al. (12), that support this prediction are only available at low shear rates. In this study it is assumed, however, that $E q 5$ can be applied in the total region of interest for process modeling, i.e. the region between melting and gelation when high shear rates occur. Consequently, the dynamic viscosity will be modeled as a function of effective shear rate, temperature and conversion.

Early, simple, chemorheological models, as e.g. reviewed by Roller (8), related viscosity $(\eta)$ to time $(t)$ and temperature $(T)$, but could only describe viscosity under isothermal conditions. The later, somewhat more sophisticated models, as, for example, the models of Tungare et al. (14) and Martin et al. (15), extended these equations, using an integral formulation, allowing the whole temperature history to be taken into account. No knowledge about, or control over, the conversion $(\alpha)$ as a function of time $(t)$ is assumed. Using independently measured kinetic data, $\eta(t)$ can be converted into $\eta(\alpha)$. Lipschitz (16) and Macosko (17) reported a molecular model, using a branching theory, which relates the conversion, $\alpha$, to the molecular weight $\left(M_{w}\right)$. These molecular models can only be used when sufficient information is available concerning the components of the compound and the actual reactions that occur during cure.

Unfortunately, commercial molding compounds contain several epoxies and hardeners, and a high content of various additives that might affect the reactions. Therefore, a model based on a molecular analyses is often found to be impracticable.

Another class of models relates viscosity directly to conversion [Castro et al. (18), Frutiger (19), Manzione et al. (20)]. In these models, an Arrhenius type of temperature dependency is assumed with two adjustable parameters. The models differ in their treatment of this curing dependency but all assume that it can be separated from the temperature dependency. Furthermore, these models do not include a shear rate dependency. For filled systems, however, pronounced shear thinning has been observed, by, for example, Macosko et al. (17).

The nonlinear behavior of the viscosity as a function of the shear rate can often be described by means of a power law. We use such an expression to model the effective shear rate dependence. Temperature dependence is described by an Arrhenius equation, and, therefore, the following expression for the dynamic viscosity is adopted:

$$
\eta\left(T, \omega \gamma_{0}\right)=\eta_{0} e^{E_{\eta} / R T} *\left(\omega \gamma_{0}\right)^{n}
$$


The material parameters, $\eta_{0}, E_{\eta}$, and $n$, represent the pre-exponential factor, the flow activation energy and the power law exponent, respectively. In case of reacting materials, these material parameters will be, in general, a function of the conversion. Thus, Eq 6 is written as:

$$
\eta\left(\alpha, T, \omega \gamma_{0}\right)=\eta_{0}(\alpha) * e^{E_{\eta}(\alpha) / R T} *\left(\omega \gamma_{0}\right)^{n(\alpha)}
$$

The dynamic viscosity is measured at different heating rates and various frequencies and strains, producing a set of data containing viscosity, temperature, frequency, strain, and time. With the measured thermal history, and using the kinetic equation, obtained from the dynamic DSC-experiments, the conversion at each time can be calculated. Accordingly, the material parameters are determined as a function of conversion by analyzing the data at equal conversion.

\section{Experimental}

Dynamic viscosity measurements are performed on a Rheometrics Mechanical Spectrometer (RDS II), using a 25-mm-diameter plate-plate geometry. Pellets of the compound are ground into a fine powder, and, subsequently, pressed into $25 \mathrm{~mm}$ diameter discs with a height of $1.2 \mathrm{~mm}$. Care is taken not to heat the sample during milling. The pressure used is such that, in the final discs, a specific weight of $1.7 \mathrm{~g} / \mathrm{cm}^{3}$ is obtained, equal to the density of the preforms used in the encapsulation process. This proved to be rather important since the density has a large influence on the values measured for the dynamic viscosity. The viscosities are measured at constant heating rates of $2,5,10$, and $20^{\circ} \mathrm{C} / \mathrm{min}$ at various frequencies and strains.

\section{Results and Discussion}

In Fig. 4 the dynamic viscosity is plotted vs. temperature, measured at a heating rate of $2^{\circ} \mathrm{C} / \mathrm{min}$, a max-

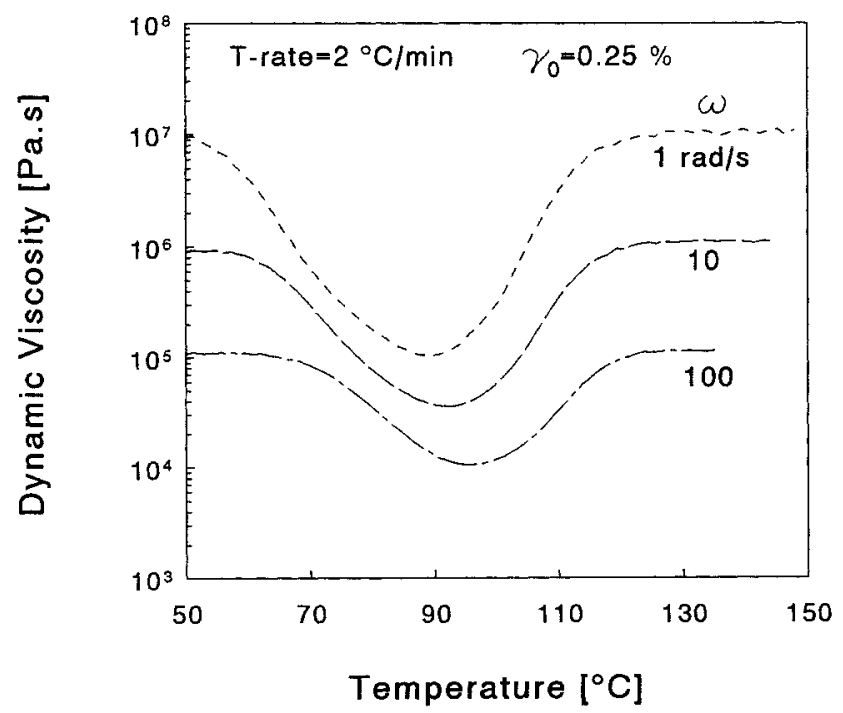

Fig. 4. Dynamic viscosity as a function of temperature, measured at a heating rate of $2^{\circ} \mathrm{C} / \mathrm{min}, \gamma_{0}=0.25 \%$, and $\omega=1,10$, and $100 \mathrm{rad} / \mathrm{s}$. imum strain of $0.25 \%$ and frequencies of 1,10 , and $100 \mathrm{rad} / \mathrm{s}$. In Fig. 5 the dynamic viscosity is plotted as a function of temperature, at $20^{\circ} \mathrm{C} / \mathrm{min}, 100 \mathrm{rad} / \mathrm{s}$, and strains of 0.25 and $1 \%$. It is clear that the material not only shows a frequency dependence but also a pronounced strain dependence. At a heating rate of $5^{\circ} \mathrm{C} / \mathrm{min}$, experiments are performed at various frequencies and strains, to determine whether the material follows the predictions of the model of Doraiswamy et al. (12), implying that curves with the same effective shear rate superimpose. In Fig. 6 the dynamic viscosity is plotted against temperature for constant effective shear rate $\left(\omega \gamma_{0}\right)$, and indeed, the data for each effective shear rate form a single master curve, in the range between melting and gelation. It is important to note that other predictions of the constitutive model, as proposed by Doraiswamy et al. (12), are not fulfilled. For example, the phase shift $\delta$ should be a function of the imposed strain: $\delta=\cos ^{-1}[1-$ $\left(2 \gamma_{c} / \gamma_{0}\right]$, where $\gamma_{c}$ is the strain at yielding. This is not confirmed for the material under consideration.

Using the kinetic equation obtained in section 2.2 , at each point of the $\eta\left(T, \omega \gamma_{0}, \dot{T}\right)$ curves the conversion can be calculated, and points of equal conversion can be determined. In Fig. 7 the results are shown for the experiments performed at a heating rate of $5^{\circ} \mathrm{C} / \mathrm{min}$. Over a range of conversions, the dynamic viscosity is plotted against the effective shear rate in Fig. 8. The slope of the isoconversion lines in the double logarithmic plot provides the value of the power law exponent from $E q$ 7. It is clear that the exponent is not a constant, since it decreases with conversion. The power law exponent is determined as a function of the conversion at each heating rate, see Fig. 9. The differences, due to different heating rates, are neglected and a third order polynomial is fitted on the average values to obtain a description of the power law exponent as a function of the conversion, see Table 2.

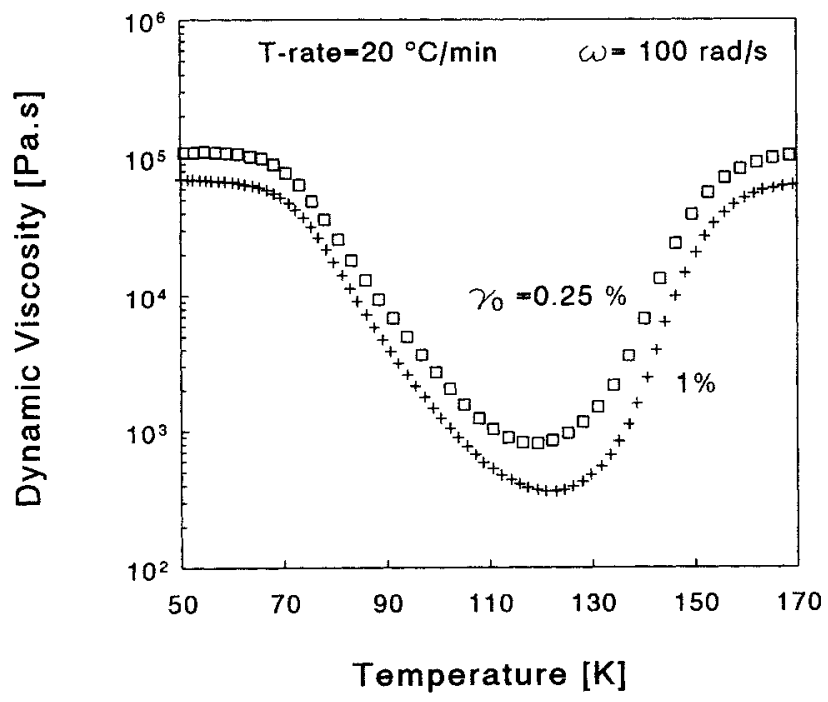

Fig. 5. Dynamic viscosity measured as a function of temperature, at a heating rate of $20^{\circ} \mathrm{C} / \mathrm{min}, \omega=100 \mathrm{rad} / \mathrm{s}$ and $\gamma_{0}=$ $0.25(\square)$ and $1 \%(+)$. 


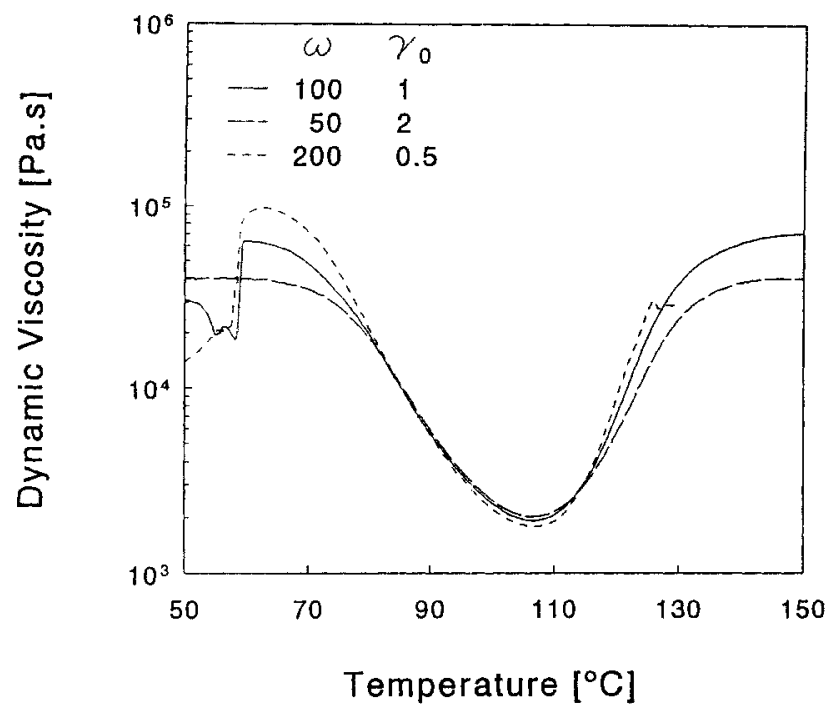

Fig. 6. Dynamic viscosity us. temperature for constant effective shear rate $\left(\omega \gamma_{0}=100 \mathrm{~s}^{-1}\right)$ at a heating rate of $5^{\circ} \mathrm{C} / \mathrm{min}$.

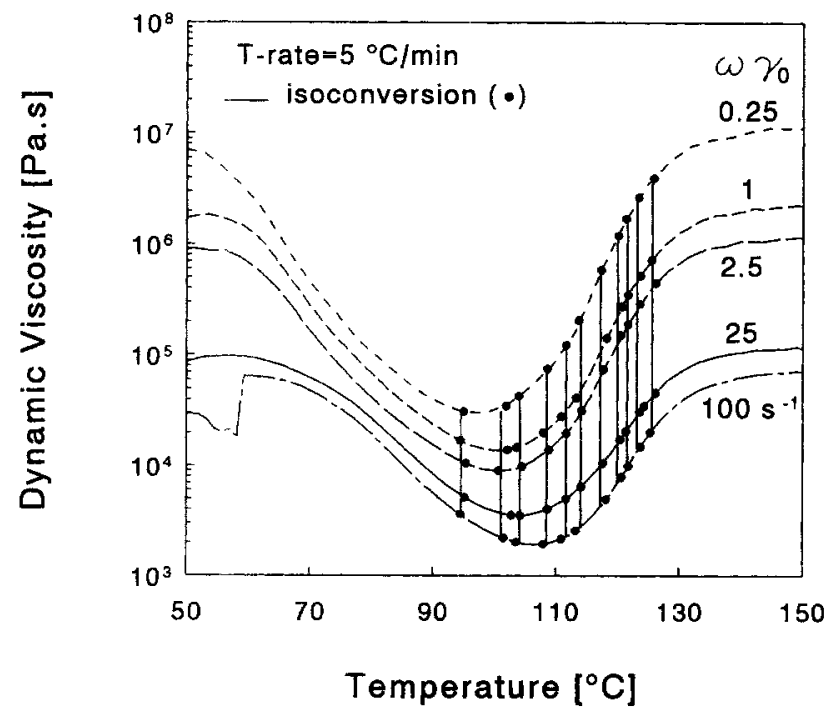

Fyg. 7. Dynamic viscosity plotted against the temperature for experiments performed at a heating rate of $5^{\circ} \mathrm{C} / \mathrm{min}$ and different effective shear rates; Thick full lines are lines of equal conversion (0.001 $<\alpha<0.3$, see caption of Fig. 8).

For different values of the effective shear rate the dynamic viscosity was measured at different heating rates $\left(2,5,10\right.$, and $\left.20^{\circ} \mathrm{C} / \mathrm{min}\right)$. In $F i g .10$ the dynamic viscosity is plotted against the reciprocal temperature for experiments performed at an effective shear rate of $25 \mathrm{~s}^{-1}$. Lines of equal conversion were determined, using the kinetic equation and the given temperature history, and are plotted in Fig. 10 as well (thick lines). The slope of these lines $\left(E_{\eta} / R\right)$ appears to depend on the conversion. Consequently the temperature and conversion dependencies cannot be separated. The conversion dependent flow activation energy $\mathrm{Eq} \mathrm{7}$, is determined by fitting a ninth order polynomial to the average values of the curves shown in Fig. 11. Since the power law exponent was already calculated over a

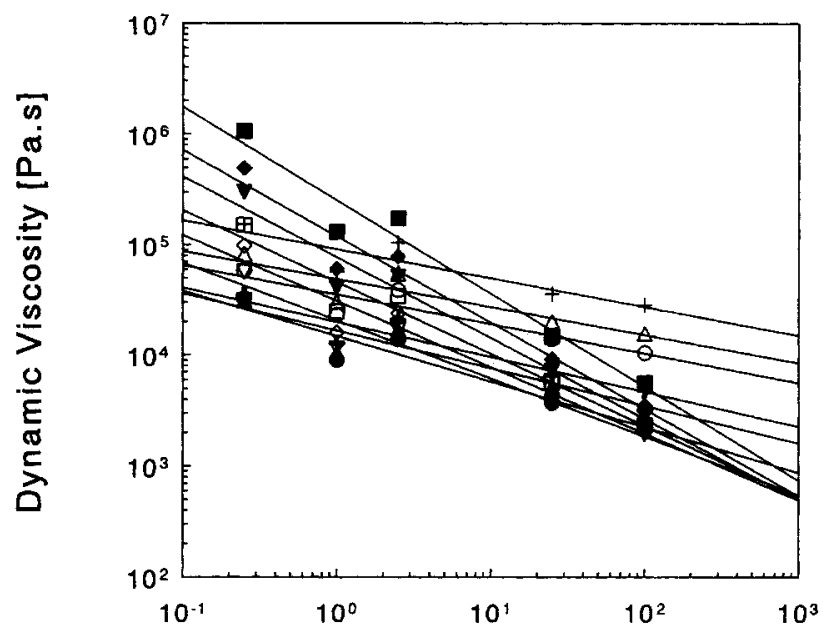

Effective Shear rate $\left[s^{-1}\right]$

Fig. 8. Dynamic viscosity as a function of the effective shear rate for various conversions: $0.001(+) ; 0.002(\triangle) ; 0.003(0)$; $0.01(+) ; 0.02(\Delta) ; 0.04(0) ; 0.06(\nabla) ; 0.08(\diamond) ; 0.10(\square) ; 0.12$ $(\nabla) ; 0.14(\diamond) ; 0.18(\square)$. Full lines are isoconversion lines.

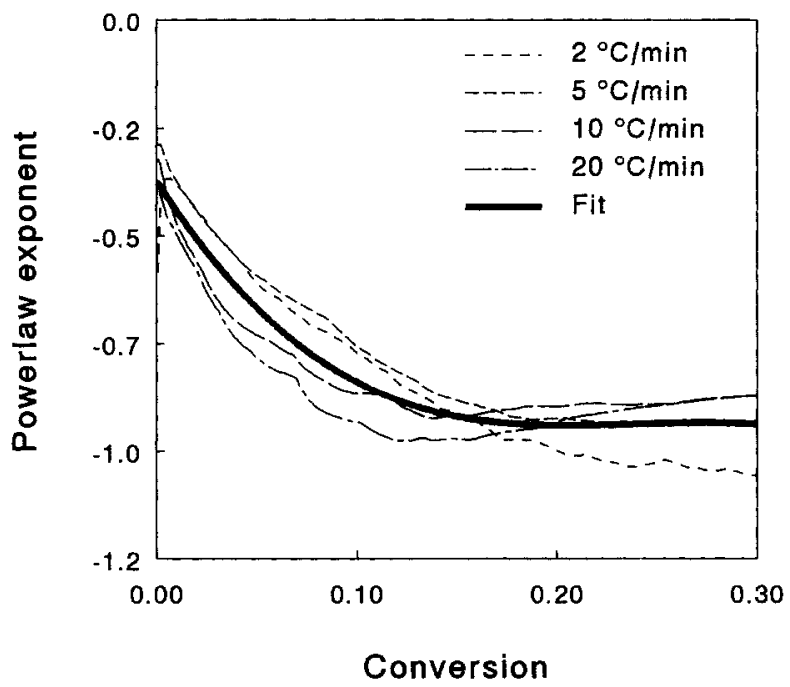

Fig. 9. Power law exponent (n) us. conversion obtained from experiments performed at different heating rates. Thick full line is a third order polynomial fitted on the average values.

range of conversions, the pre-exponential factor $\left(\eta_{0}\right)$ can be determined as well using an identical procedure (Fig. 12). The coefficients of the polynomials obtained by fitting the conversion dependent factors, can be found in Table 2. Combining the effective shear rate dependence, as described with the power law, with the temperature and conversion dependence, as described with the Arrhenius equation, see $E q 7$, a complete description of the dynamic viscosity as a function of effective shear rate, temperature, and conversion is found.

To study the predictive capabilities of the description obtained, the dynamic viscosity of independent experiments are calculated. Using the temperature history of the experiments, the conversion at each time is calculated with the kinetic equation obtained. 
A. B. Spoelstra, G. W. M. Peters, and H. E. H. Meijer

Table 2. Coefficients of Polynomial Fits on the Parameters $E_{\eta}(\alpha), \ln \eta_{0}(\alpha)$ and $n(\alpha)$ in the Viscosity Model.

$\mathbf{P}(\alpha)=c 0+c 1 \alpha+c 2 \alpha 2+c 3 \alpha 3+c 4 \alpha 4+c 5 \alpha 5+c 6 \alpha 6+c 7 \alpha 7+c 8 \alpha 8+c 9 \alpha 9$

\begin{tabular}{|c|c|c|c|}
\hline coefficients & $E_{\eta}$ & $\ln \eta_{0}$ & $n$ \\
\hline $\begin{array}{l}c_{9} \\
c_{8} \\
c_{7} \\
c_{6} \\
c_{5} \\
c_{4} \\
c_{3} \\
c_{2} \\
c_{1} \\
c_{0}\end{array}$ & $\begin{array}{r}-2.8944736 e+11 \\
3.85088790 e+11 \\
-2.1489223 e+11 \\
6.6218237 e+10 \\
-1.2642624 e+10 \\
1.6141442 e+09 \\
-1.4453929 e+08 \\
9.0527915 e+06 \\
-4.2472636 e+05 \\
1.7367610 e+04\end{array}$ & $\begin{array}{r}7.7970068 e+08 \\
-1.0439793 e+09 \\
5.8797321 e+08 \\
-1.8352803 e+08 \\
3.5610406 e+07 \\
-4.6181142 e+06 \\
4.1683219 e+05 \\
-2.6059090 e+04 \\
1.2246353 e+03 \\
-3.7808040 e+01\end{array}$ & $\begin{array}{c}0 \\
0 \\
0 \\
0 \\
0 \\
0 \\
-4.2140983 e+01 \\
3.0273505 e+01 \\
-7.1070750 e+00 \\
-3.5431100 e-01\end{array}$ \\
\hline
\end{tabular}

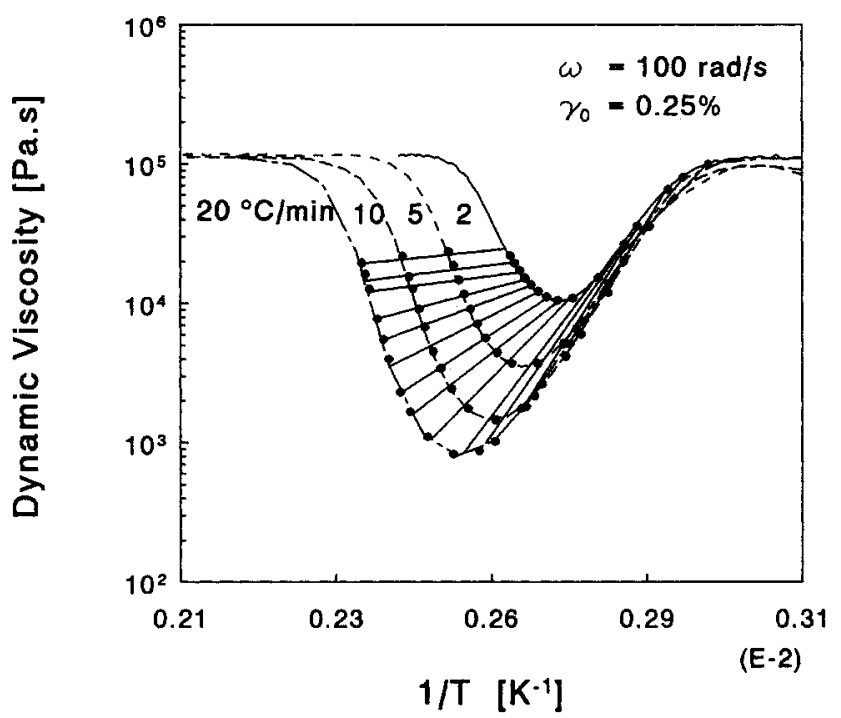

Fig. 10. Dynamic viscosity plotted us. the reciprocal temperature, for experiments performed at $\gamma_{0}=0.25 \%$, and $\omega=100$ $\mathrm{rad} / \mathrm{s}$ and different heating rates $\left(2,5,10,20^{\circ} \mathrm{C} / \mathrm{min}\right) ;$ Thick full lines are lines of equal conversion.

The calculation of the dynamic viscosity is started after melting and before gelation of the material $\left(\alpha_{\text {gel }}=\right.$ 0.18 , see below). The measured viscosity is compared with the calculated viscosity in Fig. 13, and agrees well.

\section{GEL POINT}

\section{Theory}

Gelation is of critical importance in the processing of thermosets, since beyond this point the polymer does not flow and is, consequently, no longer processable. Gelation does not inhibit the curing kinetics and, therefore, cannot be detected by techniques that are only sensitive to the chemical reaction, such as DSC. The gel point is defined by the conversion at which an infinite molecular network is formed. Prior to gelation, the polymer is soluble, but after gelation both soluble (sol fraction) and insoluble (gel fraction) materials are present [Bidstrup (21)].

As a result of the infinite molecular network formed, the steady state viscosity would become infinite at the

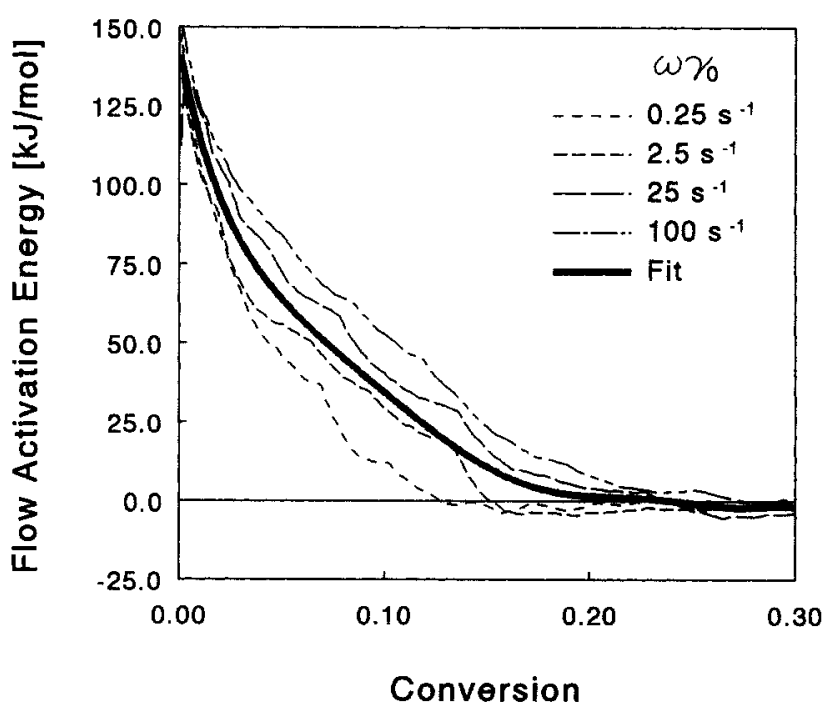

Fig. 11. Flow activation energy vs. conversion, obtained from experiments performed at different effective shear rates. Thick full line: ninth order polynomial fit on the average values.

gel point. The dynamic viscosity per definition never becomes infinite, however, even after gelation. In the literature various methods have been proposed to determine the gel point, for unfilled amorphous polymers, from dynamic measurements. Tung and Dynes (1) suggested that the $G^{\prime}-G^{\prime \prime}$ crossover point corresponds to the gel point. Winter et al. $(2,3)$, however, argued that the correspondence is only valid for a limited class of network polymers. Different classes are distinguished by their stress relaxation behavior near the gel point. As a consequence, Chambon and Winter (22) proposed a general method for detecting gelation from dynamic experiments. According to this theory, $\tan (\delta)$ is independent of the frequency at gelation, the gel point may be determined by performing experiments at different frequencies. Another method for detecting the gel point from dynamic experiments is proposed by Harran et al. (23). They found that gelation may be detected by the appearance of a shoulder in the $G^{\prime \prime}$ curve. Further, they observed that the position of this shoulder is not influenced by frequency or strain, supporting the statement of Winter.

In the following, the gel point is determined first by measuring the soluble fraction of samples with a dif- 


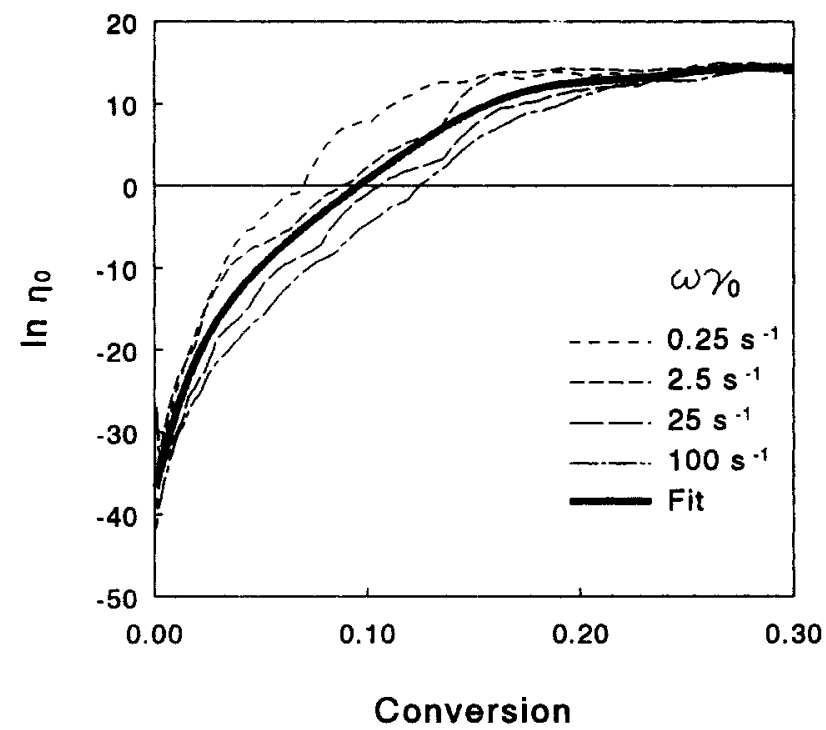

Flg. 12. Pre-exponential factor us. conversion, obtained from experiments performed at different effective shear rates. Thick full line: ninth order polynomial fit on the average values.

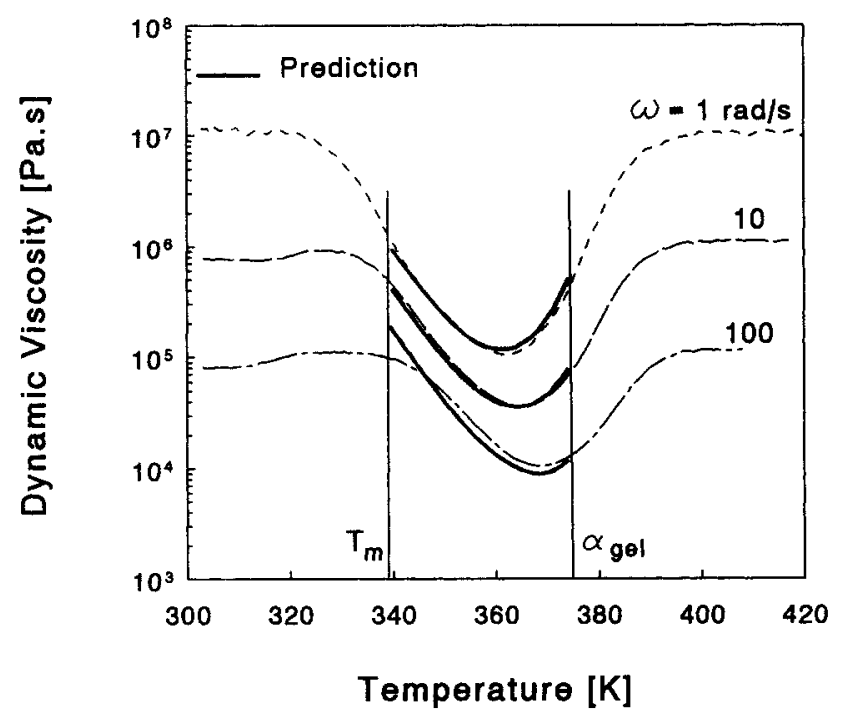

Fig. 13. Independent data on the dynamic viscosity vs. temperature, for a heating rate of $2^{\circ} \mathrm{C} / \mathrm{min}, \gamma_{0}=0.25 \%$, and $\omega=$ 1. 10 , and $100 \mathrm{rad} / \mathrm{s}$; (--): measured, (-): predicted.

ferent degree of cure. The conversion of these samples is determined by measuring the heat of reaction left, using DSC. Next, the theories proposed in literature to determine the gel point from rheological measurements are examined.

\section{Soxhlet Extraction}

The amount of sol fraction can be determined through extraction. When the sample is merged into a suitable solvent, all finite molecules will dissolve and diffuse out of the sample. By applying Soxhlet extraction, the solvent is exchanged continuously and eventually no sol fraction will remain. Samples are prepared by curing small amounts of compound on a metal plate in an oven at $90^{\circ} \mathrm{C}$ for various times. The reaction is stopped by quenching. A small amount of these samples are fully cured in the DSC to determine the degree of reaction. Following the procedure of Bidstrup (21), cellulose thimbles are extracted for $72 \mathrm{~h}$ in tetrahydrofuran and then dried under vacuum. The samples with various curing times are placed in a pre-extracted thimble and extracted in tetrahydrofuran for $96 \mathrm{~h}$ and dried under vacuum until no further weight loss can be detected. The weight fraction of soluble components $\left(W_{s}\right)$ is calculated as follows:

$$
W_{s}=\frac{W_{\text {before extraction }}-W_{\text {after extraction }}}{W_{\text {before extraction }}}
$$

In Fig. 14 the soluble fraction of the samples, cured for different times, are shown as a function of the conversion, as determined with DSC-experiments. In the pre-gel region, all molecules are finite and dissolve during extraction. The value for the soluble fraction of $33 \mathrm{wt} \%$, measured in this region, is in reasonable agreement with the fact that, according to the specifications of the compound, $69 \mathrm{wt} \%$ of the compound consists of insoluble silica. In the post-gel stage, the soluble fraction decreases with conversion until no more solubles are present. Samples were prepared with a conversion around the point of gelation until the difference in conversion of the last pre-gel sample and the first post-gel sample is less than $5 \%$. The gel point is then defined as the average of the conversion of these two samples, and is found to be located at a conversion of 0.18 .

\section{Viscoelastic Properties Near the Gel Point}

To examine if the theories, proposed in the literature to detect the gel point from dynamic experiments, hold for the material under consideration, the dynamic viscosity is studied. Tung and Dynes (1) suggested that the $G^{\prime}-G^{\prime \prime}$ crossover corresponds to the gel

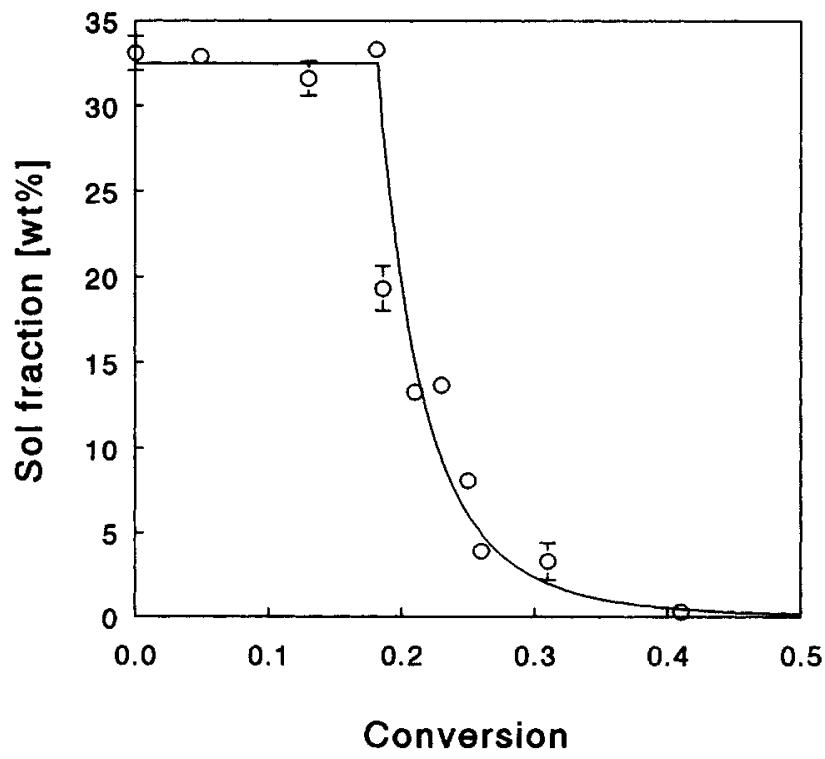

Fig. 14. Soluble fraction of samples cured for different times plotted against the conversion. 
point. In Fig. $15 G^{\prime}$ and $G^{\prime \prime}$ are plotted against temperature for measurements performed at a heating rate of $2^{\circ} \mathrm{C} / \mathrm{min}, 0.25 \%$ strain, and frequencies of 1,10 , and $100 \mathrm{rad} / \mathrm{s}$. It is shown that, despite the identical temperature histories of the experiments, the $G^{\prime}-G^{\prime \prime}$ crossover does not occur at the same temperature and, since the temperature histories are similar, not at the same level of cure.

In Table 3 the conversions at the $G^{\prime}-G^{\prime \prime}$ crossover, calculated with the kinetic equation, are listed for all experiments performed. Since gelation should only depend on temperature history, it is clear that the gel point does not correspond with the $G^{\prime}-G^{\prime \prime}$ crossover. According to Winter's findings $(2,3), \tan (\delta)$ is independent of frequency at the gel point. In Fig. $16, \tan (\delta)$ is plotted vs. conversion. At a conversion of 0.02 the curves cross, and thus in that point $\tan (\delta)$ is found to be independent of the frequency. For other series of experiments, such a point could not be detected unambiguously. Although for a conversion of \pm 0.18 , the gel point as detected by extraction experiments, some $\tan (\delta)$ curves cross over. Winter's approach seems, however, not consistent for the whole range of experiments performed on this type of materials.

It appears that none of the methods proposed in the literature is capable of detecting the gel point from dynamic experiments for the system used in our study. Probably the high level of additives, especially the high percentage of solid particles, cause the models to fail for the epoxy compound studied.

However, evaluating the dynamic results, we found that above a certain degree of reaction, the storage modulus, $G^{\prime}$, is no longer a function of frequency or temperature. This is shown in Fig. 17, where $G^{\prime}$ is plotted against the conversion for dynamic experiments conducted at a maximum strain of $0.25 \%$ with various heating rates and frequencies. All $G^{\prime}$ curves converge after a defined level of cure is reached.

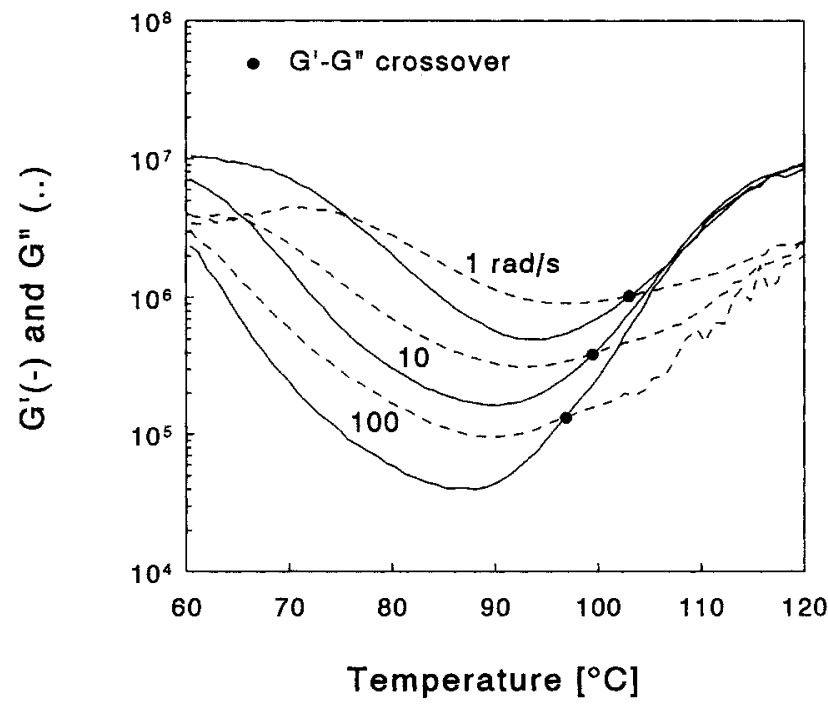

Fig. 15. $G^{\prime}($.$) and G^{\prime \prime}(-)$ measured at a heating rate of $2^{\circ} \mathrm{C} / \mathrm{min}$ plotted against temperature; $\gamma_{0}=0.25 \%$, and $\omega=1,10$, and $100 \mathrm{rad} / \mathrm{s}$; (O): $G^{\prime}-G^{\prime \prime}$ crossover.
Table 3. Conversion at the $G^{\prime}-G^{\prime \prime}$ Cross-over for the Rheological Measurements Performed at Various Heating Rates, Frequencies, and Maximum Strains.

\begin{tabular}{ccccc}
\hline $\begin{array}{c}\text { T-rate } \\
{\left[{ }^{\circ} \mathbf{C} / \mathbf{m i n}\right]}\end{array}$ & $\begin{array}{c}\omega \\
{[\mathbf{r a d} / \mathrm{s}]}\end{array}$ & $\begin{array}{c}\gamma_{0} \\
{[\%]}\end{array}$ & $\begin{array}{c}\omega \gamma_{0} \\
{\left[\mathbf{s}^{-1}\right]}\end{array}$ & $\begin{array}{c}\boldsymbol{\alpha}_{\text {cross- }} \\
\text { over }\end{array}$ \\
\hline 2 & 1 & 0.25 & 0.25 & 0.061 \\
2 & 10 & 0.25 & 2.5 & 0.088 \\
2 & 100 & 0.25 & 25 & 0.134 \\
5 & 1 & 0.25 & 0.25 & 0.046 \\
5 & 1 & 1 & 1 & 0.074 \\
5 & 4 & 0.25 & 1 & 0.057 \\
5 & 10 & 0.25 & 2.5 & 0.049 \\
5 & 50 & 2 & 100 & 0.132 \\
5 & 100 & 0.25 & 25 & 0.087 \\
5 & 100 & 1 & 100 & 0.131 \\
5 & 200 & 0.5 & 100 & 0.131 \\
10 & 1 & 0.25 & 0.25 & 0.045 \\
10 & 10 & 0.25 & 2.5 & 0.039 \\
10 & 50 & 2 & 100 & 0.103 \\
10 & 100 & 0.25 & 25 & 0.074 \\
10 & 100 & 1 & 100 & 0.094 \\
20 & 1 & 0.25 & 0.25 & 0.047 \\
20 & 10 & 0.25 & 2.5 & 0.036 \\
20 & 50 & 2 & 100 & 0.094 \\
20 & 100 & 0.25 & 25 & 0.053 \\
20 & 100 & 1 & 100 & 0.085 \\
\hline
\end{tabular}

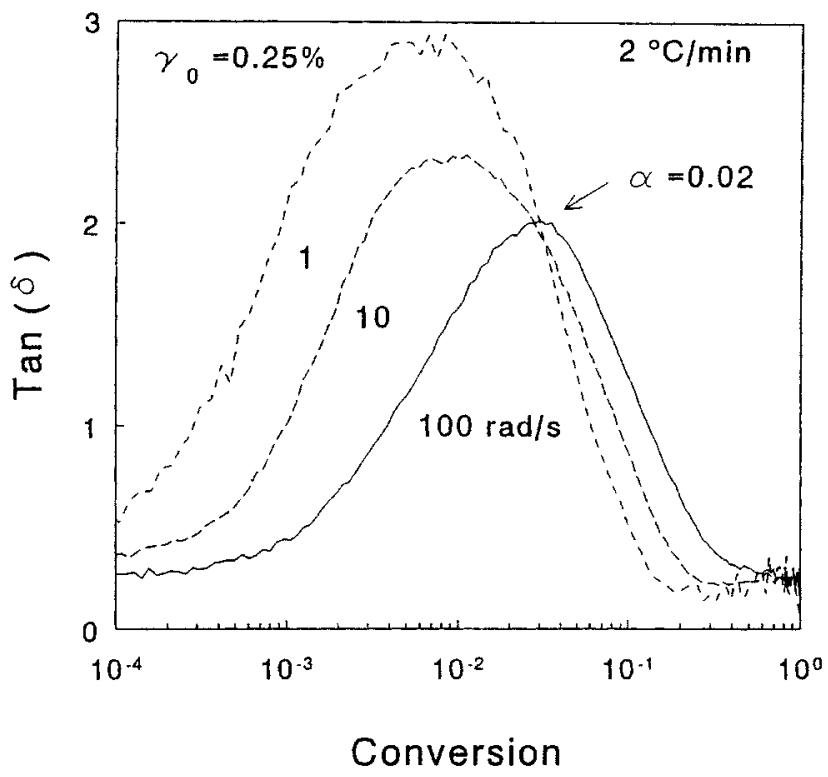

Fig. 16. Tan ( $\delta$ ) us. conversion; heating rate of $2^{\circ} \mathrm{C} / \mathrm{min}, \gamma_{0}=$ $0.25 \%$, and $\omega=1,10$, and $100 \mathrm{rad} / \mathrm{s}$.

It is known that beyond gelation, in the rubbery state, $G^{\prime}$ is hardly dependent on frequency and temperature [Ferry (24)]. Before gelation, however, pronounced temperature and frequency dependencies are to be expected. This means that the conversion at which the curves converge corresponds with the gel point. From Fig. 17 it appears that the conversion at convergence is in reasonable agreement with the gel point as determined through extraction experiments $\left(\alpha_{\text {gel }}=0.18\right)$. Unfortunately, the transition is not evident enough to serve as an unambiguous technique to detect the gel point. Moreover, the maximum strain influences the $G^{\prime}$ curve, as shown in Fig. 18, where $G^{\prime}$ 


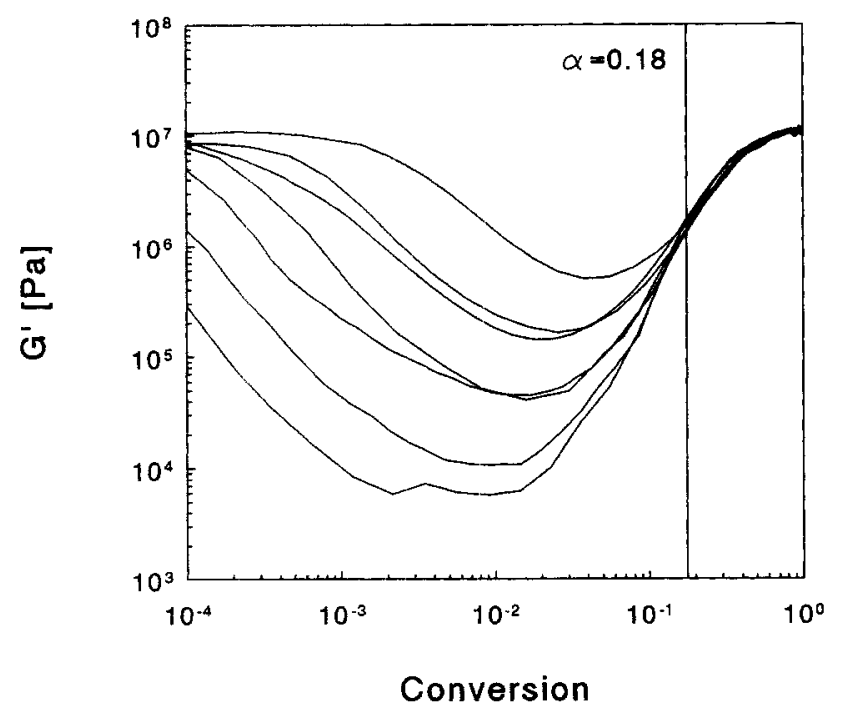

Fig. 17. $G^{\prime}$ us. the conversion for dynamic experiments performed at $\gamma_{0}=0.25 \%$, and at various combinations of frequencies and heating rates.

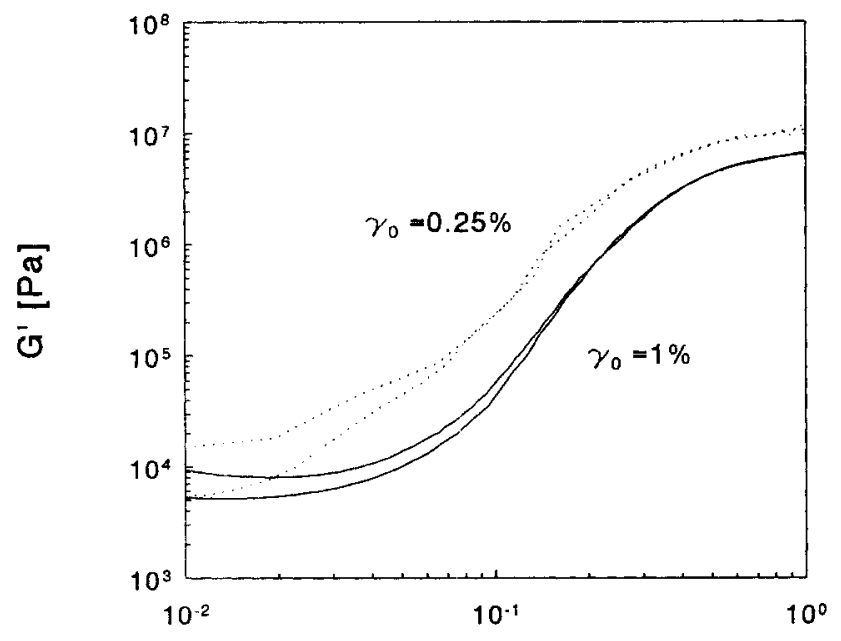

\section{Conversion}

Fig. 18. $G^{\prime}$ us. conversion for dynamic experiments performed at $\gamma_{0}=0.25 \%(.$.$) and 1 \%(-)$.

is plotted against conversion for experiments performed at different strains. The strain dependency illustrates the nonlinear behavior of this crosslinked system.

\section{CONCLUSION}

A procedure is proposed to find an expression relating the viscosity of a complex epoxy compound during cure, to the temperature, shear rate, and degree of reaction. It appeared that at a constant value of the effective shear rate (i.e. the product of frequency and strain) the dynamic viscosity is identical over a wide range of frequencies, strains, and temperatures. The effective shear rate dependence of the viscosity is described with a power law with an exponent that depends on the conversion. The effect of temperature is described with an Arrhenius-type equation with conversion dependent parameters. Differential scanning calorimetry is applied to determine the kinetic equation, which is used in combination with the thermal history to obtain the conversion during the rheological measurements. The description of the viscosity gives a good prediction of the measured viscosity in the region between melting and gelation of the compound.

The gel point of the highly filled epoxy system is studied using extraction experiments, and by examining the viscoelastic properties near the gel point. In the theories proposed in the literature to detect the gel point from dynamic experiments, it is observed that neither the $G^{\prime}-G^{\prime \prime}$ crossover nor the frequency-independency of the loss angle $\tan (\delta)$ can be used to determine the gel point of the system studied. This could be due to the high filling content of solid additives in this compound. However, the curves of $G^{\prime}$ against conversion for measurements performed at an equal maximum strain appear to converge after a conversion is reached of $\sim 0.18$, which agrees with the gel point determined through extraction experiments.

In this study it is assumed that in the region of interest of process modeling, i.e. the region between melting and gelation of the epoxy compound, an equivalence exists between the steady state viscosity $\eta_{s}(\dot{\gamma})$ and the dynamic viscosity $\eta_{d}\left(\omega \gamma_{0}\right)$. This assumption can be validated by using the obtained viscosity model in a numerical simulation of flows that can be compared with experimental results. Such a study was done by Peters et al. (25). They found that the behavior of this material is even more complex than the dynamical measurements show. From this combined numerical/experimental study, it appeared that the material already behaved as if it was gelled at a conversion level of 0.03 . As this gelling was only seen in flow visualization experiments and not in DSC, DMTA, or extraction experiments, it was called a rheological gelpoint, to contrast with the clearly found chemical gelpoint.

\section{NOMENCLATURE}

\section{Reaction Kinetics}

$E_{1}, E_{2}=$ Activation energies.

$\Delta H=$ Total heat production during cure.

$K_{1}, K_{2}=$ Rate constants.

$k_{1}, k_{2}=$ Pre-exponential factors.

$M_{w}=$ Molecular weight.

$m, n=$ Reaction orders.

$R=$ Gas constant.

$T=$ Temperature.

$t=$ Time.

$\alpha=$ Conversion.

$\dot{\alpha}=$ Conversion rate.

\section{Rheology}

$E_{\eta}=$ Flow activation energy.

$G^{\prime}=$ Storage modulus.

$G^{\prime \prime}=$ Loss modulus. 
$n=$ Powerlaw exponent.

$\dot{T}=$ Temperature rate.

$\delta=$ Phase shift.

$\eta=$ Viscosity.

$\eta_{0}=$ Pre-exponential factor.

$\eta_{d}=$ Dynamic viscosity.

$\eta_{s}=$ Steady state viscosity.

$\gamma=$ Strain.

$\gamma_{0}=$ Maximum strain.

$\gamma_{c}=$ Strain at yielding.

$\dot{\gamma}=$ Strain rate.

$\omega=$ Frequency.

\section{REPERENCES}

1. C. Y. M. Tung and P. J. Dynes, J. Appl. Polym. Scl., 27. 569 (1982).

2. H. H. Winter, SPE ANTEC Tech. Papers, 33, 300 (1987).

3. H. H. Winter and F. Chambon, J. Rheol., 30, 367 (1986),

4. A. Hale, M. Garcia, C. W. Macosko, and L. T. Manzione, SPE ANTEC Tech. Papers, 35, 796 (1989).

5. T. H. Hsieh and A. C. Su, J. Appl. Polym. Sci., 41, 1271 (1990).

6. M. R. Kamal and S. Sourour, Polym. Eng. Sci., 13, 59 (1973).

7. R. B. Prime, Thermal Characterization of Polymeric Materials, E. A. Turi, ed., Academic Press, New York (1981).

8. M. B. Roller, Polym. Eng. Sct., 28, 432 (1986).

9. W. P. Cox and E. H. Merz, J. Polym. Sct., 28, 619 (1958).

10. T. Kitano, T. Nishamura, T. Kataoka, and T. Sakai, Rheol. Acta, 19,671 (1980).
11. D. M. Bigg, Polym. Eng. Sct, 28, 206 (1983).

12. D. Doraiswamy, I.-L. Tsao, S. C. Danforth, A. N. Beris, and A. B. Metzner, Proc. Xth Int. Congress on Rheology, 1, 300 (1988)

13. B. J. van den Brule, J. F. Dijksman, and P. J. Zander, Rheol. Acta, 26, 186 (1988).

14. A. V. Tungare, G. C. Martin, and J. T. Gotro, Polym. Eng. Sci., 28, 1071 (1989).

15. G. C. Martin, A. V. Tungare, and J. T. Gotro, Polym. Eng. Sct., 29, 1279 (1989).

16. S. D. Lipschitz and C. W. Macosko, Polym. Eng. Sci., 16. 803 (1976).

17. C. W. Macosko, Brit. Polym., 17, 239 (1985).

18. J. M. Castro and C. W. Macosko, SPE ANTEC Tech. Papers, 26, 434 (1980).

19. R. L. Frutiger, Polym. Eng. Sci., 26, 243 (1986).

20. L. T. Manzione, G. W. Poelzing, and R. C. Progelhof, Polym. Eng. Sct., 28, 1056 (1988).

21. S. A. Bidstrup, PhD thesis, Univ. Minnesota (1986).

22. F. Chambon and H. H. Winter, J. Rheol., 31, 683 (1987).

23. D. Harran, A. C. Senhaji, and G. Marin, Proc. Xth Int. Congress on Rheology, 1, 300 (1988).

24. J. D. Ferry, Viscoelastic Propertles of Polymers, John Wiley \& Sons, New York (1978).

25. G. W. M. Peters, A. B. Spoelstra, M. H. H. Meuwissen, R. Corbey, and H. E. H. Meijer, Toplcs in Applted Mechanics, pp. 331-38, J. F. Dijksman and F. T. M. Nieuwstadt, eds., Kluwer Academic Publishers. The Netherlands (1993). 